\title{
Describing Ethiopian Bookbinding in TEI
}

\author{
Eliana Dal Sasso
}

\section{OpenEdition \\ Journals}

Electronic version

URL: https://journals.openedition.org/jtei/3790

DOI: 10.4000/jtei.3790

ISSN: 2162-5603

Publisher

TEl Consortium

\section{Electronic reference}

Eliana Dal Sasso, "Describing Ethiopian Bookbinding in TEI", Journal of the Text Encoding Initiative [Online], Rolling Issue, Online since 22 January 2022, connection on 14 January 2023. URL: http:// journals.openedition.org/jtei/3790 ; DOI: https://doi.org/10.4000/jtei.3790

For this publication a Creative Commons Attribution 4.0 International license has been granted by the author(s) who retain full copyright. 


\title{
Describing Ethiopian Bookbinding in TEI
}

\author{
Eliana Dal Sasso
}

\section{ABSTRACT}

Ethiopian bookbinding is one of the material expressions of the ancient manuscript culture of Ethiopia and Eritrea, which is the research field of the Beta mașāhəft project. Despite the significance of the materials and techniques adopted in bookbinding manufacture for the understanding of the manuscript they enclose, they have never been systematically recorded, until very recently. The present paper introduces the Beta mașāhoft project's innovative approach to bookbinding descriptions and its customization of the TEI schema to record the small variations of Ethiopian bookbinding elements. Since a standard vocabulary for Ethiopian bookbinding features was lacking, Beta mașāhaft developed a tailored taxonomy to create consistent descriptions. The encoding of the binding occurs in the <binding $>$ element, within which $a<$ decoNote $>$ element is assigned to each significant bookbinding feature. The descriptions consist partly of free text and partly of markup using keywords enforced by the taxonomy. This paper presents some applications 
offered by the Beta mașāhaft project that use the recorded bookbinding features, and it shows how the encoding of this large amount of previously ignored data could open new research perspectives on Ethiopian book production.

\section{INDEX}

Keywords: Ethiopian Studies, bookbinding, manuscripts, vocabulary, TEI customization

\section{ACKNOWLEDGEMENTS}

The research for this paper was funded by the Deutsche Forschungsgemeinschaft (DFG, German Research Foundation) under Germany's Excellence Strategy - EXC 2176 "Understanding Written Artefacts: Material, Interaction and Transmission in Manuscript Cultures," project no. 390893796. The research was conducted within the scope of the Centre for the Study of Manuscript Cultures (CSMC) at Universität Hamburg.

\section{The Role of Bookbinding Studies in Understanding the}

\section{Manuscript}

1 Looking at the codex as an object, one of its most noticeable-if present-yet overlooked attributes is its binding. Bookbindings capture onlookers' gaze and through their design, they convey specific messages without needing the book to be opened. Paraphrasing Rousseau $(2007,1)$, it is possible to note that bindings can inspire religious veneration or aesthetic admiration, or simply manifest the purpose for which the manuscript was created. The information transmitted by the binding varies according to the materials and techniques adopted in the manufacture, which are determined by temporal and local factors. The choice of materials depends on what can be found at a precise moment in the place of production. Techniques, imparted by tradition, evolve across time, taught by one generation to the next, and assume distinctive traits according to the area to which they belong. Hence, the characterization of the materials and techniques helps to locate and date the production of the binding, while their fineness offers clues to the prestige of a manuscript, to 
its use, and to the context in which it is produced or transformed. ${ }^{1}$ Therefore, to understand the information transmitted through the binding, a careful examination of the materiality of the codex is necessary.

\section{Bookbinding Recording: The State of the Art}

Despite their significance for the study of the context of production, use, and transformation of the manuscripts they enclose, bindings have never been systematically recorded (Pickwoad 2012). This situation was common to all material aspects of the codex until scholars recognized the importance of codicology for a holistic understanding of the manuscript.

3 Yet additional factors delayed the development of bookbinding studies in particular, as, for example, the scarcity of original bindings. ${ }^{2}$ In fact, as a practice, bindings had been thrown away and replaced with new ones when they had deteriorated too much to perform their protective function or simply when their design grew out of fashion. The finely decorated covers escaped this fate more often than the plain ones did, which partly explains why the first studies on bookbindings focused on their aesthetics. Far more common is the case in which the bindings have been preserved thanks to the repairs they underwent through time-which, however, also significantly altered their original structure. To detect the modifications to which a binding had been subjected, distinguishing strata of original and altered elements, a certain familiarity with the methods of creating the codex is required. However, the domain of book technology has been for a long time a prerogative of craftsmen rather than scholars involved in manuscript studies. Therefore, the description of structural elements of bindings, when given, was mostly brief and inconsistent, and so of little use for research purposes. The lack of data regarding bookbinding structures constitutes a further obstacle to the development of research in the field.

4 As interest in the materiality of the codex grew, structural elements of the binding received greater attention and pioneer scholars included them in their observations. The book started to be considered valuable not only for the text it carries, but also for its materiality, which bears witness to historical, economic, technological, and artistic aspects of the context in which it has been produced and used. This awareness led the English bookbinders Roger Powell (1896-1990) and Sydney Morris Cockerell (1906-1987) to develop a new approach to book conservation. The aim was to preserve the original elements as much as possible, balancing the need to use the 
book with the need to preserve it from further damage. Such a methodology was passed on to the conservators who gathered in Florence after the Arno's flood in 1966 to repair the damaged books of the Central National Library, thus marking the start of modern conservation practice (Campagnolo 2020,55-60). The study of bookbinding structures made it possible to to highlight the presence of recurring patterns and to group bindings accordingly, thus identifying macro-areas corresponding to different bookbinding traditions (Coptic, Ethiopic, Islamic, Byzantine, etc.). In this context, Janos A. Szirmai's work stands as a milestone in the systematization of bookbinding studies (Szirmai 1999).

5 Recently, digital technologies have improved the quality of bookbinding records. In 2001, their application in the Saint Catherine's Project ${ }^{3}$ resulted in the development of a consistent terminology-the Language of Bindings thesaurus ${ }^{4}$ (Velios, Pickwoad, and Martin 2014; Velios and Pickwoad 2020) - and a database (Velios and Pickwoad 2005) for the collection and ordering of the surveyed data (Pickwoad 2004). After creating a relational database, Ligatus developed an XML schema to describe bookbinding structures (Campagnolo 2015a, 141-145; Ligatus 2007). The experience strongly encouraged the improvement of efficient documentation systems to obtain consistent descriptions to share with the research community and overcome the long-standing absence of binding descriptions in manuscript catalogs (Campagnolo 2017). In this framework, the Beta mașāhaft ${ }^{5}$ project, whose aim is to provide a digital research environment for the exhaustive description of the written heritage of Christian Ethiopia and Eritrea, set up a protocol for bookbinding description. This paper presents how the project customized the TEI schema to encode peculiar features of Ethiopian bookbindings and collect consistent and accurate data useful for future research.

\section{The Object of Inquiry: Ethiopian Bookbinding}

6 Ethiopic manuscripts were said to be "bound in a very simple codex form, which has in fact remained almost unchanged until the present day" (Szirmai 1999, 45), but recent studies have pointed out the existence of some previously unrecorded characteristics (Di Bella and Sarris 2014; Nosnitsin 2016) that would make us reconsider what we know about Ethiopian bookbinding. Indeed, it is not an immutable tradition but the technical and aesthetic variations are limited to detail. 
An in-depth description of Ethiopian bookbinding ${ }^{6}$ features is beyond the scope of this paper. Therefore, the general characteristics of Ethiopian binding will be only briefly introduced to highlight, for each structural component, the possible existing variants. This will make it possible to understand the challenge faced by the Beta mașāheft project in setting up a protocol to encode every binding in detail without renouncing the principle of consistency, and possibly to record enough of those small variations to prove the idea of their relevance.

8 The ancient tradition of bookmaking has been handed down, and is practiced still today, in monastic centers as part of religious education (Bausi et al. 2015, 168-70). Traditionally, the quires, after being written and decorated, are sewn together to the boards with a paired link-stitch. ${ }^{8}$ Within this general category Bozzacchi $(2000,2007)$, in his study on fifty-six Ethiopic codices kept at the Library of the Accademia Nazionale dei Lincei e Corsiniana in Rome, was able to identify and describe twelve different sewing patterns. The variability of the structures depends on the number of sewing stations ${ }^{9}$ of the codex (see figure 1)-and thus on its dimensions-and on how the front board is attached to the first quire. Bozzacchi found that the binder could start sewing either from the center of the first quire or from the upper board. The thread used for sewing can be of animal (see figure 1)-probably sinew or gut-or vegetable origin. In recent times the use of synthetic fibers has also been documented (Bausi et al. 2015, 173).

Figure 1. Sewing on four sewing stations with a thread of animal origin (Grottaferrata, Exarchic Greek Abbey of St. Mary of Grottaferrata, Crypt. Aet. 7$)^{10}$.

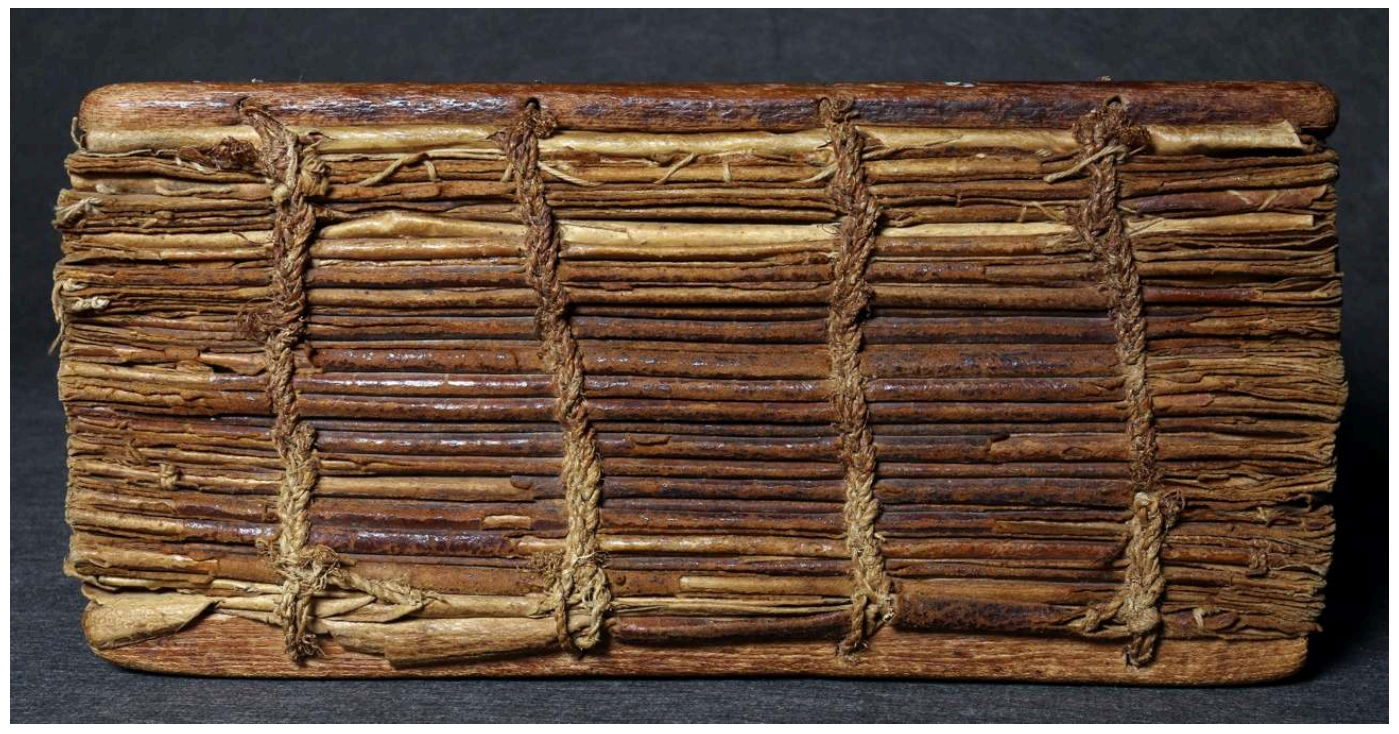

Journal of the Text Encoding Initiative, Issue rolling, 22/01/2022 Open Issue 
9 Ethiopic codices are generally bound in wooden boards. Literature reports that the most-used wood types for producing the boards are Cordia africana, Olea africana, and cedarwood. However, Mellors and Parsons (2002) and Mersha Alehegne (2011) documented the use of thirteen further wood types. In some cases, the boards are made of stiff leather instead of wood, perhaps hinting at the need to use a less expensive material (Nosnitsin 2016, 81).

10 Wooden boards can be left bare or be covered with leather. Commonly the cover extends over the entire board but, as highlighted recently (Bausi et al.2015,172; Nosnitsin 2016,78), in some cases it covers only the spine and the back edge of the boards. Covering material that exceeds the size of the boards is folded over to form turn-ins. ${ }^{11}$ The shape of these turn-ins varies enormously in the ways in which they are trimmed or overlapped. Furthermore, textiles of varying quality can inlay the inner surface of the boards (see figure 2). A less common feature is the presence in this area of a mirror, the function of which is still not clear. The cover is then often embellished with blindtooled decoration $^{12}$ using a variety of tools. Despite some authors dedicating part of their research to the study of these tools (Sergew Hable Selassie 1981; Faqāda Śellāse Tafarrā 2010; Winslow 2015; Tomaszewski and Gervers 2015), a comprehensive classification system has not yet been developed. Even less is known about the recurring decorative patterns and layout of the covers. ${ }^{13}$ In a few cases the boards are covered with metal sides ${ }^{14}$ or bear metal bosses (Bausi et al. 2015, 172). 
Figure 2. Textile inlay on the inner upper board and a parchment guard along the fold of the first quire (Exarchic Greek Abbey of St. Mary of Grottaferrata, Crypt. Aet. 7).

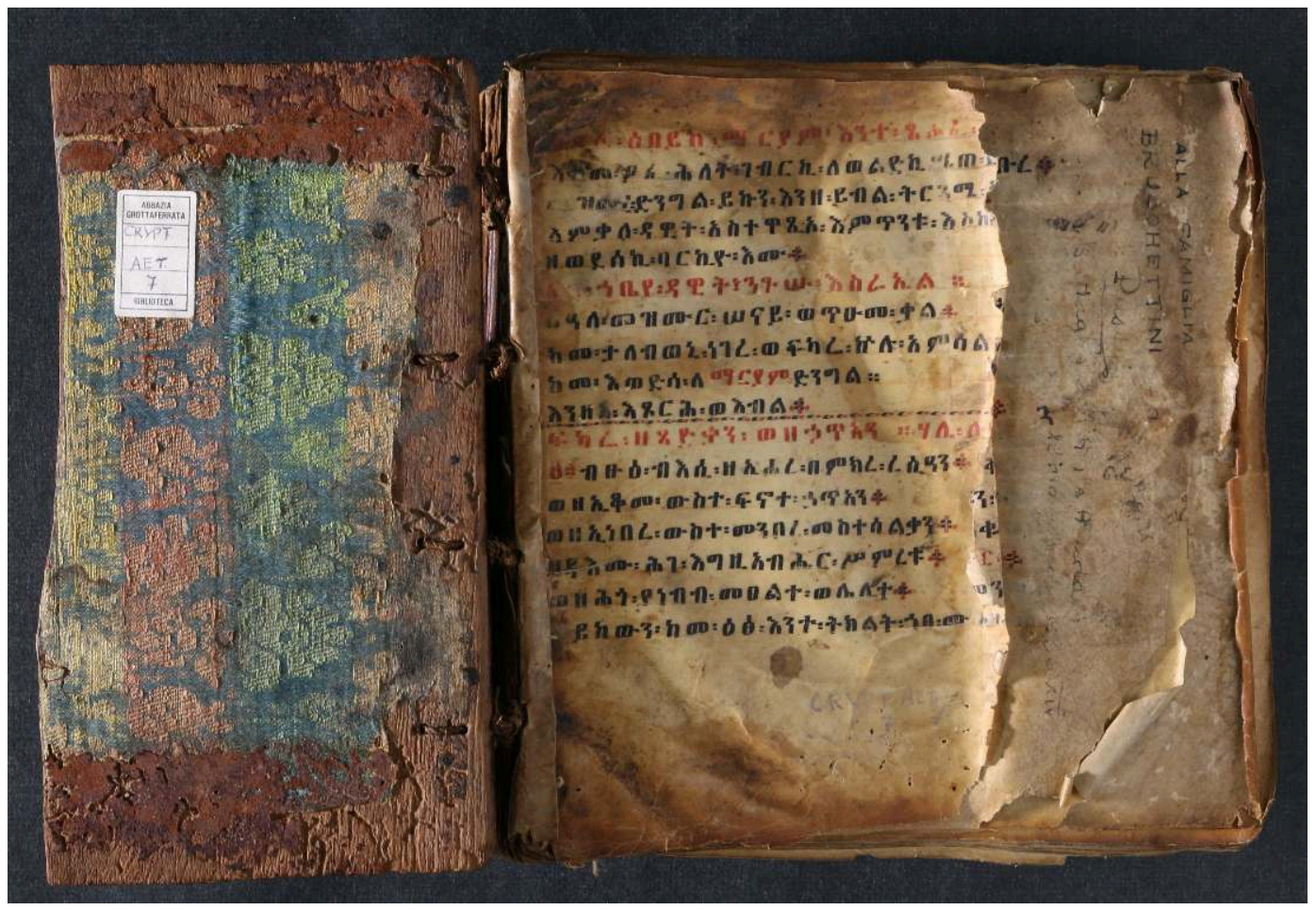

Usually, endbands ${ }^{15}$ made of slit-braided leather tongues are added to the leather-covered codices, but a less common type, similar in technique to a Coptic one (Szirmai 1999, 39, fig. 3.7a), has been documented on two manuscripts with bare boards (Di Bella and Sarris 2014, 293, fig. 27b).

Sources of variance depend on other features, related to:

- $\quad$ Pastedowns ${ }^{16}$ and their position in relation to turn-ins;

- The spine, such as the presence of a piece of parchment folded around the text block and sewn with the first and last quire as a sort of spine lining $^{17}$ (Di Bella and Sarris 2014, 301). In particular, the presence of rows of holes close to the head and tail of the quires is important. This feature can be related to the former presence of endbands or tackets (Bausi et al.2015, 159);

- $\quad$ Fastenings or traces of them (Di Bella and Sarris 2014,299);

- $\quad$ Parchment guards ${ }^{18}$ (see figure 2), their position and technique of attachment to the quire; - $\quad$ Bookmark types;

Journal of the Text Encoding Initiative, Issue rolling, 22/01/2022 Open Issue 
- The traditional two-part leather slip case (Bausi et al. 2015, 172).

\subsection{A Taxonomy for the Description of Ethiopian Bookbinding Features}

13 The first step in the development of consistent descriptions is the use of a controlled vocabulary. The adoption of a selected terminology avoids the confusion which arises when different terms are used to describe the same concept. Therefore, a controlled vocabulary increases the efficiency of the documentary system by limiting data redundancy. Furthermore, the homogeneous descriptions created following this method have the great advantage of being easily comparable, thus making it easier to identify similarities and differences in a group of items.

14 For this purpose, the terminology used in binding descriptions (<bindingDes $c>)^{19}$ in Beta mașāhaft is partly enforced by the schema, customized so to pick up keywords from a specifically conceived taxonomy. The Beta mașāḥft taxonomy included in each XML file within the element <taxonomy> contains a main <category $>$ for binding.

The taxonomy is hierarchically structured so that broader <category> elements corresponding to selected bookbinding features (that is, sewing pattern, thread material, wood type, board lining, decoration motives, endband type, guards, and bookmarks) include one or more child <category> elements corresponding to keywords which describe the possible variants of that feature (see example 1).

\section{Example 1. Part of the taxonomy dedicated to the category Endband Type.}

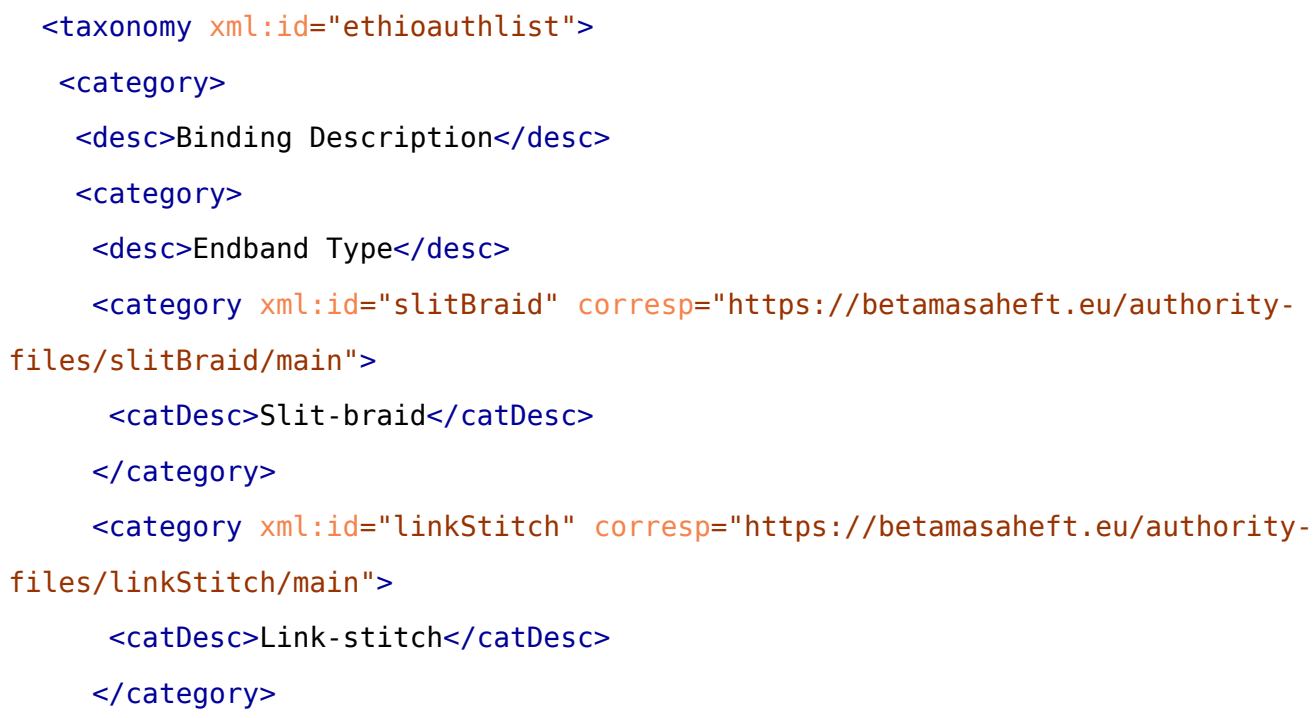

Journal of the Text Encoding Initiative, Issue rolling, 22/01/2022 


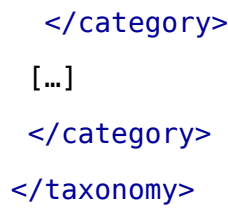

16 Each keyword in the taxonomy corresponds to a file in the authority-files repository of the project, which is also a TEI file, to accommodate future information about each of these concepts. Authority files for binding description reflect the hierarchical structure of the taxonomy. They usually contain just a $<$ title $>$, a brief explanation of what the keyword stands for, and the bibliographic references for the concept. This also makes the concept a published, versioned, citable entity on the web with a stable identifier.

17 Keywords are indexed in the Beta mașāhəft web application so that the user can visualize which bookbinding features are taken into consideration in manuscript records and which keywords are used to describe their possible variants. When selecting a keyword, the application displays the corresponding authority file, which also shows all the occurrences of that keyword in the manuscript records (see figure 3$)^{20}$

Figure 3. Slit-braid keyword displayed in the web application.

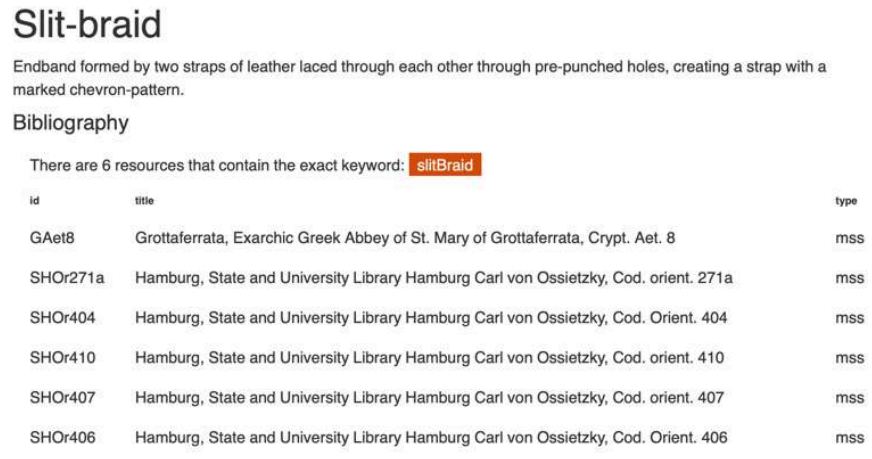

18 The keywords are also listed in the $\mathrm{ODD}^{21}$ (see figure 4). 
Figure 4. The values in the Beta mașāḥft ODD as presented in the Guidelines.

\begin{tabular}{ll} 
Endbands & $\begin{array}{l}\text { for use in binding description. Structural and } \\
\text { decorative elements of the binding which are found at } \\
\text { the head and tail of the spine of a book. The ethiopian } \\
\text { endbands are usually slit-braid stripes of leather or } \\
\text { link-stitch sewings. }\end{array}$ \\
\hline Fastening & $\begin{array}{l}\text { for use in binding description. Stripe of different form } \\
\text { and material used to keep closed a book. Traces of } \\
\text { fastenings can be holes and pins on the outer edge of } \\
\text { the boards. }\end{array}$ \\
\hline Spine & $\begin{array}{l}\text { for use in binding description. The part of the book } \\
\text { opposite the fore-edge. }\end{array}$ \\
\hline SlipCase & for use in binding description. Portable leather case \\
with attached slip where the manuscript is kept.
\end{tabular}

19 Since the aforementioned Language of Bindings thesaurus (LoB) describes in detail many aspects of ancient book structures, Beta mașāḥft uses it as much as possible in its controlled vocabulary. When the concept expressed by a keyword can be related to a LoB one, the authority file is set to provide the link to the LoB URI as well. The alignment with LoB is done-like other alignments in Beta mașāhəft-with < relation>. The @name attribute permits one to specify the semantic relationship between Beta mașāhoft and LoB concepts by using the SKOS ${ }^{22}$ semantic relation skos:broader or choosing a value from the SKOS mapping properties skos: exactMatch and skos : broadMatch. When a Beta mașāhəft concept does not match an exact LoB concept but it is possible to establish a sematic relation with a more general LoB concept, the relation skos : broader is used. For example, Beta mașāhəft distinguishes between various hardwood types which are not defined in LoB (which lists among the hardwoods only beech and oak). In this case the Beta mașāhəft concepts declare a semantic hierarchical relation with the more general LoB concept hardwood by using the relation skos: broader (see example 3).

\section{Example 2. Use of skos:broader for the alignment to LoB.}

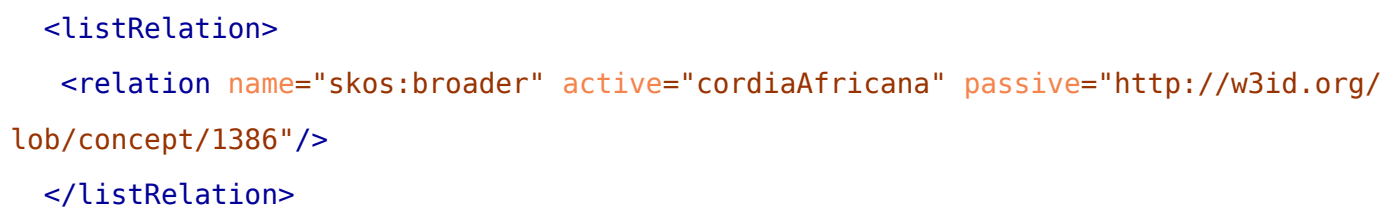

Journal of the Text Encoding Initiative, Issue rolling, 22/01/2022 
The property skos:broadMatch permits one to match a Beta mașāhəft concept with an external concept with which there is no exact correspondence. For example, LoB defines board linings as the pieces of sheet material adhered to the boards before the book is covered. ${ }^{23}$ As explained above, a common board lining in Ethiopian bookbinding tradition is made of textile. Since the concept textile in Beta mașāhoft specifically refers to the use of the material as board lining, it has a broad match with the LoB concept board lining. Nevertheless, it has a semantic exact equivalence with the LoB concept textile. ${ }^{24}$ The authority file specifies both relations using a skos : broadMatch with the LoB board lining and a skos: exactMatch with the LoB textile (see example 3).

Example 3. Use of skos: broadMatch and skos: exactMatch for the alignment to LoB.

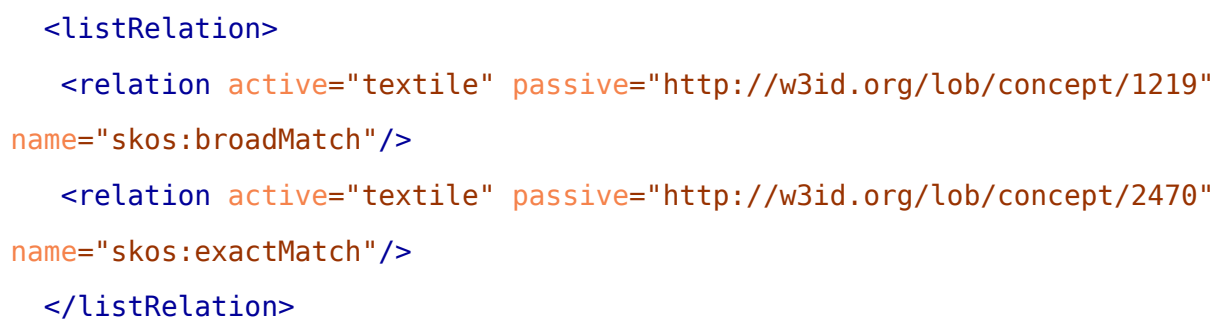

In this way the alignment to LoB occurs within the authority files and reflects directly on each manuscript entry where the file is used. This procedure regards LoB vocabulary as a semantic resource, without impacting its integrity but instead improving cooperation and reuse of open data.

Nevertheless, a standard terminology to refer to the specific characteristics of Ethiopian bookbinding tradition was still lacking. Therefore, Beta mașāḥft developed a tailored terminology to offer accurate research data to the users of the application as well as to encoders. Thus, keywords -normally chosen from among the most frequently occurring terms in the bibliography-have been discussed among Beta mașāhaft team and external contributors in issues opened in the GitHub repository page of the project. Once the group reached an agreement, the taxonomy file was edited, an authority file was created, and the ODD was updated. When necessary, parts of the Guidelines were also edited, although changes to the ODD are immediately reflected. ${ }^{25}$ 


\subsection{Bookbinding Descriptions in Beta mașāḥəft: A Customization of the TEI}

\section{Schema} Consortium 2020). Therefore, the description of the current binding of the manuscript is located in <physDesc>, within <bindingDesc>, in the element <binding>. As stated in the Guidelines, ${ }^{26}$ <binding > can take @notBefore @notAfter and @contemporary when it is possible to provide information on the dating of its manufacture.

24 To produce useful data for scholars, every relevant structural element of the binding should be described, thus encoded, separately. In this way, the data about specific features become searchable and retrievable via the web application. Beta mașāhəft and other projects have developed their own ways of meeting this requirement as well as solutions to cope with the issue. According to the TEI Guidelines, the element <binding $>$ may contain $<p>,<a b>,<$ condition $>$, and $<$ decoDesc $>$ child elements. It appears that most manuscript catalogs using TEI listed in the TEI Wiki ${ }^{27}$ have chosen to encode binding descriptions in one or more $<p>$ elements, as paragraphs of free text. ${ }^{28}$ This is the case, for example, with the projects Manuscriptorium ${ }^{29}$ and e-Codices. ${ }^{30}$ The latter does at least permit filtering the bindings according to their date and isolating the luxurious bindings (see example 4).

Example 4. Binding description in e-Codices (Appenzell, Landesarchiv Appenzell I. Rh., E.10.02.01.01) ${ }^{31}$.

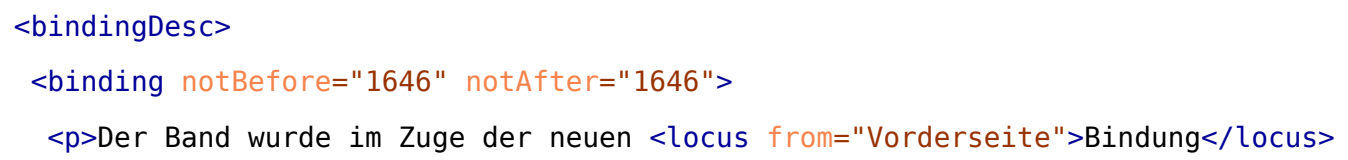

A similar approach is adopted in the ENRICH ${ }^{32}$ Schema on which the entries in Manuscriptorium are based (Driscoll 2010). According to the Reference Guide (Burnard 2008), the description of the binding is places in $<\mathrm{p}>$ elements and $<$ decoNote $>$ elements are used to describe its decorative features. 
Since the FIHRST ${ }^{33}$ and SENMAI ${ }^{34}$ union catalogs are based on a customization of the ENRICH schema, they structure the binding description uniformly. In addition, their $\mathrm{ODD}^{35}$ states that the <term> element with @type attribute marks relevant features of the binding and the aref attribute is used to refer to the appropriate URI in the Ligatus thesaurus. Nevertheless, the link does not seem to have been implemented in the records. An attempt at further structuring of binding records appears in the FIHRST description of some manuscripts in the Wellcome collection in London. Here the description of the binding is always set in $<p>$ paragraphs, but $<$ seg $>$ elements with @type and @subtype attributes permit segmenting the paragraph and describing bookbinding structural elements separately (see example 5). Nevertheless, the website does not offer a dedicated search on bookbinding features.

Example 5. Binding description in FIHRST (London, Wellcome Trust, Wellcome Collection, MS Arabic 495) ${ }^{36}$.

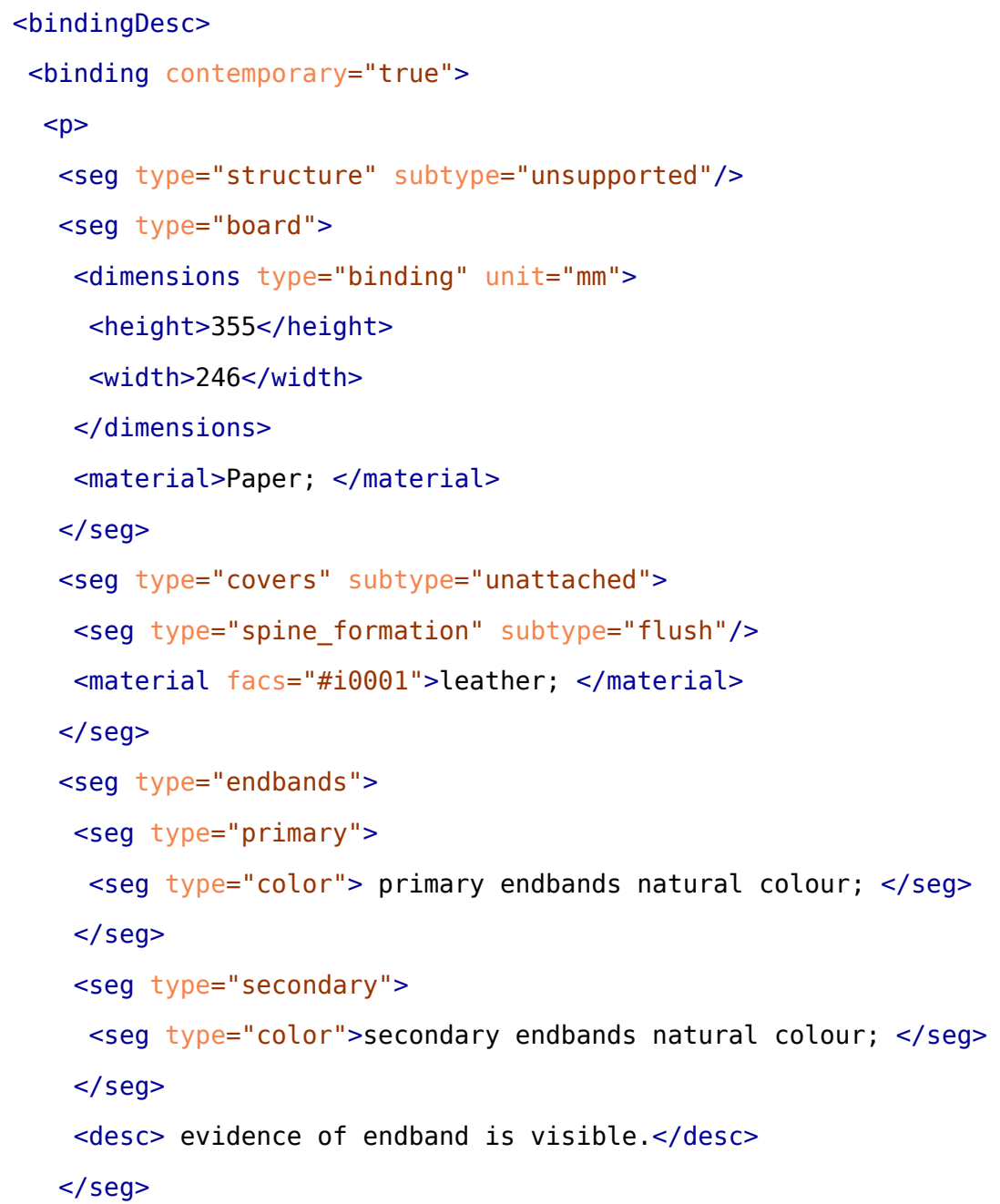

Journal of the Text Encoding Initiative, Issue rolling, 22/01/2022 


$$
\begin{gathered}
</ p> \\
</ \text { binding }> \\
</ \text { bindingDesc }>
\end{gathered}
$$

A customization of the TEI schema is also used for manuscript descriptions exported from Manus Online $^{37}(\mathrm{MOL})$, the Italian national catalog of manuscripts. The binding description is arranged in $<p>$ elements where <note $>$ child elements with @n and @type attributes are added to encode the fields of MOL that do not have a corresponding tag in the TEI schema (Barbero and Trasselli 2014). In this way the boards and cover can be described separately (see example 6).

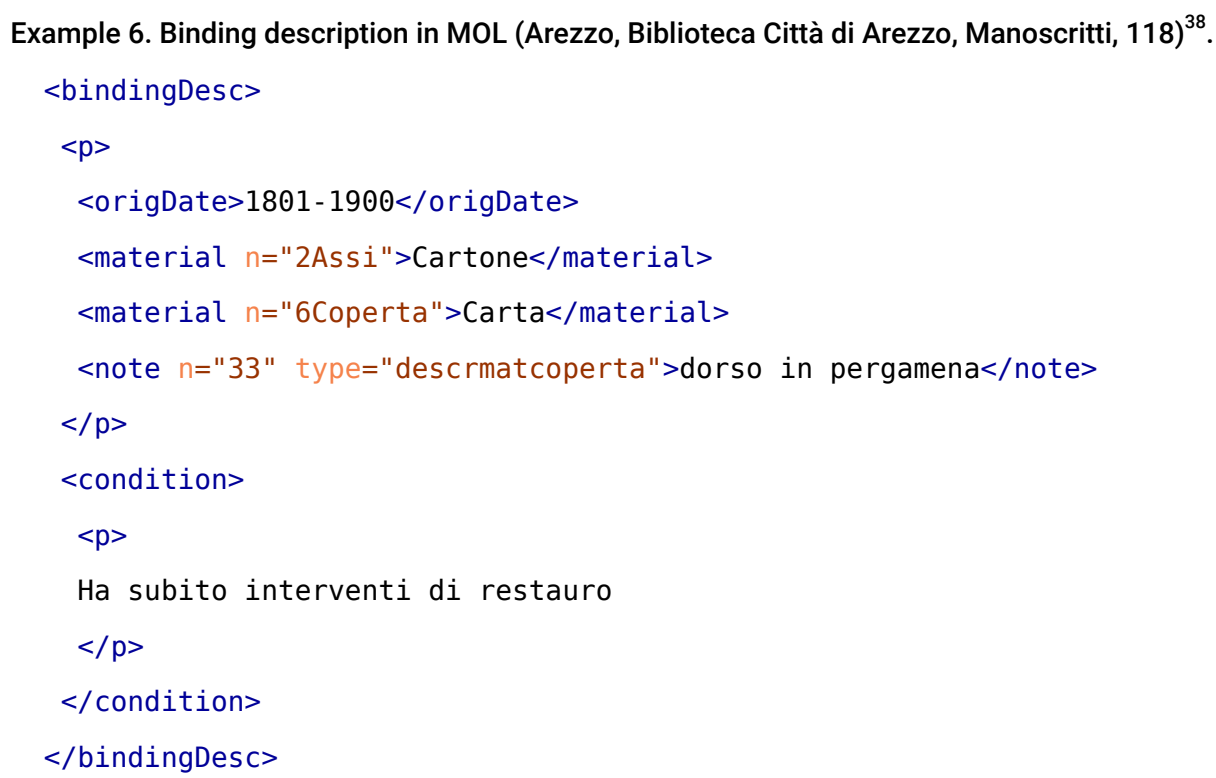

28 The Bibliothèque national de France $(\mathrm{BnF})$ created the website Reliures de la Bibliothèque nationale de France ${ }^{39}$ which offers a selection of digitized French bindings from BnF's collection with a detailed description, using a customization of the TEI schema. As stated in the $\mathrm{ODD}^{40}$ and explained in the manual of use (Le Bars et al. 2016), bookbinding descriptions may contain, beyond the elements expected in the TEI schema, <dimensions $>,<$ index $>,<$ globalDescription $>$, and <structure> elements. The last two elements were created as part of the project to give a summary identification and information on structural elements of the binding respectively (Campagnolo 2015b, 98-99). The <index> element takes a mandatory @indexName attribute with values controlled by the BnF Binding Scheme which serve to identify categories relative to the 
type, the technique, the material, and the place of production of the binding-in a similar way to the use made by MOL of the <note> element. An exhaustive description of the binding is based on $<$ decoNote> elements with @type attributes with values that specify the structural element being described (see example 7).

Example 7. Binding description in BnF (Paris, Bibliothèque nationale de France, Réserve des livres rares, RES P- YC- 1275) ${ }^{42}$.

$<$ bindingDesc>

$<$ binding contemporary="true">

$<p>$

<index indexName="typo_reliure">

$<$ term $>$ Reliure à décor $</$ term $>$

$</$ index $>$

$<$ index indexName="typo_decor">

$<$ term>Entrelacs géométriques</term>

$</$ index> Reliure en <material>maroquin</material> brun jaspé</p>

$<$ decoNote type="plats"> à décor d'entrelacs géométriques (structure de losange et

rectangle) complété de fers évidés.</decoNote>

$<$ decoNote type="plat sup" $>$ Titre $<$ q $>$ ivvenalis. persivs $</ q>$ et ex-libris de Jean

Grolier $<q>i o$. grolierii et amicorvm. $<$ /q $>$ dorés respectivement au centre et au bas

du plat supérieur. </decoNote>

$<$ decoNote type="plat inf">Devise de Jean Grolier $<$ q $>$ portio mea sit in terra viventivm $</ q>$ dorée au centre du plat inférieur.</decoNote>

$<$ decoNote type="dos">Dos à cinq nerfs, sans décor; simple filet doré sur chaque

nerf et en encadrement des caissons ; passages de chaînette marqués de même.</ decoNote>

<decoNote type="tranchefiles">Tranchefiles simples unicolores, vert foncé.</ decoNote>

$<$ decoNote type="coupes">Filet doré sur les coupes. $</$ decoNote $>$

$<$ decoNote type="annexes"/>

$<$ decoNote type="tranches" $>$ Tranches dorées. $</$ decoNote $>$

$<$ decoNote type="contreplats" $>$ Contreplats en vélin. $</$ decoNote $>$

$<$ decoNote type="chasses">Filet doré sur les chasses. $</$ decoNote $>$

Journal of the Text Encoding Initiative, Issue rolling, 22/01/2022 


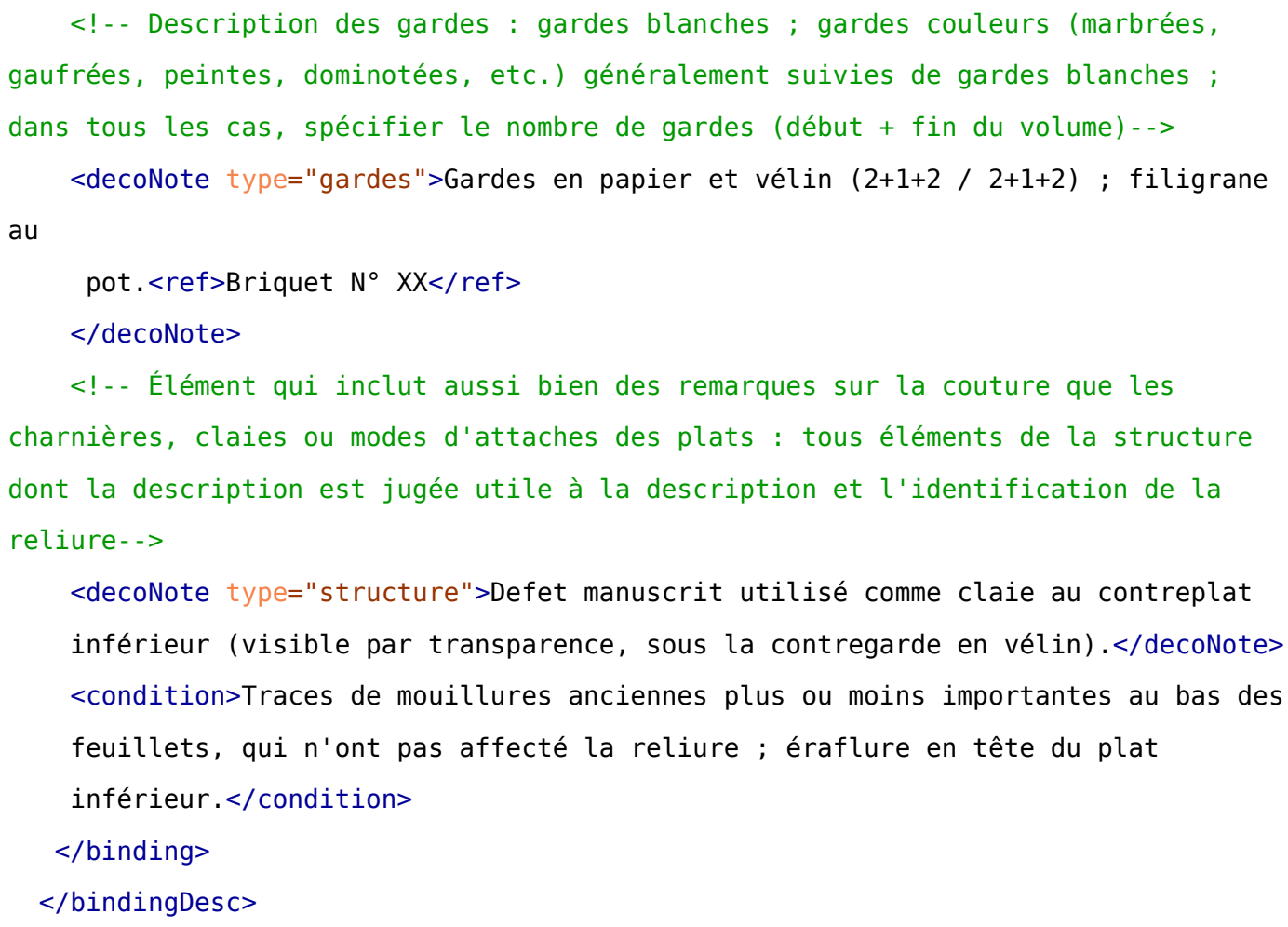

What emerges from the inquiry is that the need to encode bookbinding structural elements separately is growing, but since there is no agreed structure, the flexibility of the TEI schema permits projects to develop their own alternative solutions. The technique used is the same: projects have added a @type attribute either to the < decoNote> element or to phrase-level elements within $<\mathrm{p}>$.

Beta mașāhəft has also customized the TEI schema to adapt it to the specific needs of research on Ethiopian bookbinding. The customization of the protocol for bookbinding description started with the purpose of hosting the data inherited from the project Ethio-SPaRe ${ }^{43}$ and has been further developed within the framework of the "Torno Subito 2017" initiative. ${ }^{44}$ Despite TEI Guidelines defining the <decoNote> element as a note describing "either a decorative component of a manuscript or other object, or a fairly homogenous class of such components," ${ }^{45}$ Beta maṣāhəft, like BnF, decided to use it to describe bookbinding structural elements, as well as the decorative elements for which it is designed. The use of <decoNote> elements seemed more appropriate at 
the semantic level since the content model macro.specialPara defines them as special paragraphs which "either contain a series of component-level elements or else have the same structure as a paragraph, containing a series of phrase-level and inter-level elements. ${ }^{.46}$ Therefore, <decoNote> elements have been added where the structural element encoded is specified within a @type attribute. The permitted values, related to the main categories of interest listed above, are: binding material, boards, cover, sewing stations, endbands, endleaves, spine, fastenings, slip case, other. The descriptions partly consist of free text and partly are marked up with keywords introduced by using <term> with a @key attribute, and choosing one of the values prompted by the schema.

32 The decoNote[@type=bindingMaterial"] may contain the child element<material> to specify the materials the binding is made of, with a akey attribute equal to one of the values of the corresponding taxonomy from the schema (see example 8).

\section{Example 8. Encoding of binding material (Exarchic Greek Abbey of St. Mary of Grottaferrata, Crypt. Aet. 7).}

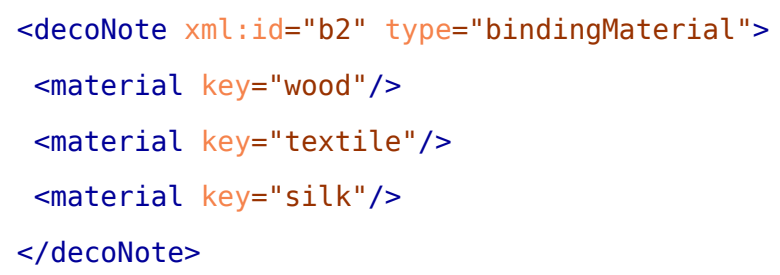

In the decoNote[@type="Boards"] it is possible to use keywords to specify the wood type-if known-and to encode the presence of a textile inlay or of a mirror (see example 9).

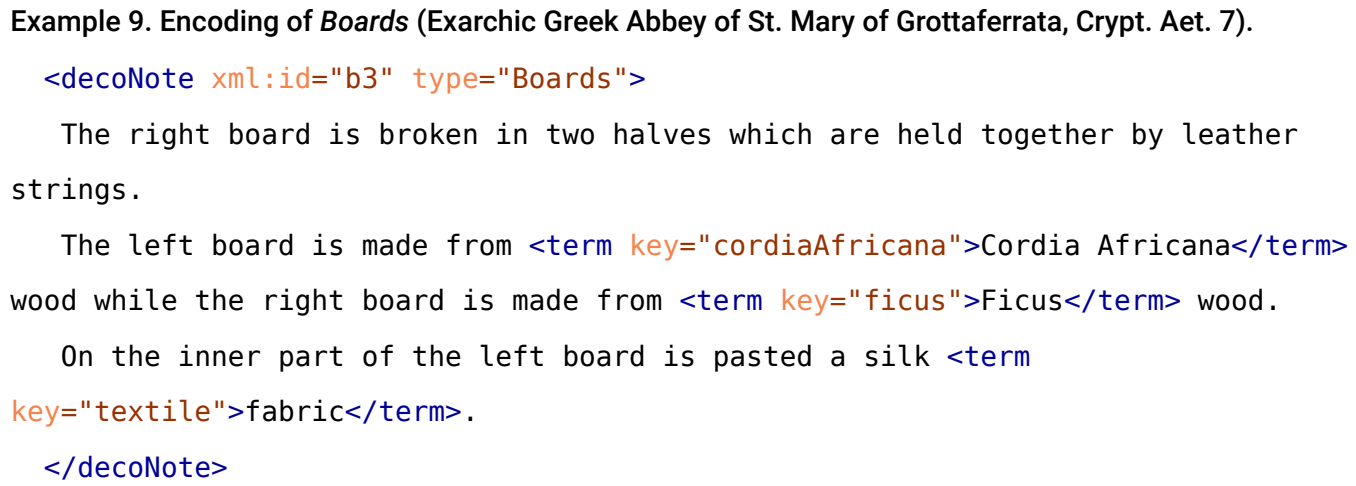


The cover can be described within the decoNote [@type="Cover"]. The color of the cover can be recorded using the attribute @color ${ }^{47}$ Keywords are used to encode the presence of an additional leather patch and describe the decoration motifs tooled on the cover. Furthermore, it is possible to specify the shape of turn-ins (see example 10).

Example 10. Encoding of Cover (Hamburg, State and University Library Hamburg Carl von Ossietzky, Cod. Orient. 404$)^{48}$.

<decoNote xml:id="b4" type="Cover">

Light brown leather cover with wide turn-ins (up to $80 \mathrm{~mm}$ ) and <term key="additionalLeatherPatch">additional leather patch</term $>$.

Among the turn-ins is pasted a <term key="textile"/>textile inlay with yellow, red and black vertical lines on a red background.

The blind-tooling decoration of the cover is imprecise and asymmetrical. The patterns on the front and back cover differ slightly.

The decorative pattern shows a latin cross surrounded by a frame. The cross occupies almost the entire central panel of the cover and is formed by the repetition of <term key="XForm" $>$ X-Form $<$ /term $>$ motifs within $<$ term key="tripleStraightLine">triple straight lines</term $>$.

The same pattern builds the outer frame.

The extant space of the cover is divided in four rectangular panels by the cross. Here, triple straight lines cross each other diagonally.

At the corners and intersections are <term key="doubleCircle">double circles</ term>, single or in groups of four.

On the turn-ins the triple straight lines follow the borders and at the intersections groups of four double circles are found.

The spine is not decorated while double circles are found on the board edges. $</$ decoNote $>$

In the decoNote [@type="Endbands"] it is possible to encode the @color of the leather straps and specify the endband type using keywords (see example 11).

Example 11. Encoding of Endbands (Hamburg, State and University Library Hamburg Carl von Ossietzky, Cod. Orient. 404).

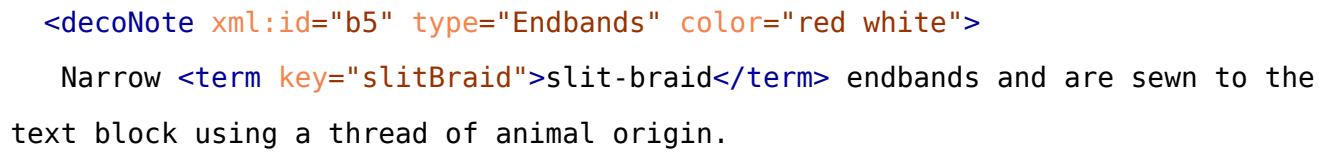

Journal of the Text Encoding Initiative, Issue rolling, 22/01/2022 
The headband is sewn starting from the upper board while the tailband is sewn starting from the lower board.

$</$ decoNote $>$

The decoNote[@type="SewingStations"] requires, by means of a schematron rule in the ODD, that its attribute be a number as attribute, which has to be equal to the number of sewing stations (see example 12).

Example 12. Encoding of Sewing Stations (Hamburg, State and University Library Hamburg Carl von Ossietzky, Cod. Orient. 404).

$<$ decoNote $x m l:$ id="b6" type="SewingStations" $>4</$ decoNote $>$

37 A further description of the sewing is possible within a general <decoNote>, where one can encode the sewing pattern with keywords-according to Bozzacchi's classification (2007) - and the origin of the sewing thread (see example 13).

Example 13. Further encoding of the sewing (Hamburg, State and University Library Hamburg Carl von Ossietzky, Cod. Orient. 404).

$<$ decoNote xml:id="b7">

The sewing is a chain-stitch on four sewing stations (two pairs). The sewing follows the <term key="patternA">pattern A</term> defined by G. Bozzacchi.

For each sewing station a thread of <term key="animalThread">animal origin</ term> has been used.

$</$ decoNote $>$

In the decoNote [@type="Endleaves"] the endleaves-if present-are described. ${ }^{49}$ It is possible to add the attribute @pastedown, newly defined in the ODD, and chose up to three values to specify their position in relation to turn-ins. Possible values are "L" (left), "R" (right), "OTI" (over the turnins), "UTI" (under the turn-ins) (see example 14).

Example 14. Encoding of Endleaves (Hamburg, State and University Library Hamburg Carl von Ossietzky, Cod. Orient. 405). ${ }^{50}$

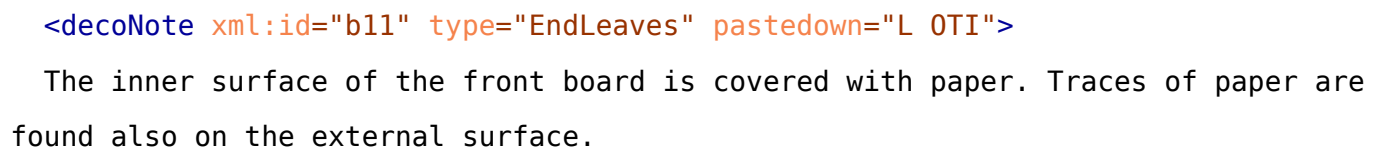

Journal of the Text Encoding Initiative, Issue rolling, 22/01/2022 
$</$ decoNote $>$

39 -can be recorded in the decoNote [@type="Spine"] (see example 15).

Example 15. Encoding of Spine (Hamburg, State and University Library Hamburg Carl von Ossietzky, Cod. Orient. 405).

<decoNote xml:id="b9" type="Spine">

Small holes are present close to the head and tail of the quires, probably remains of the tackets.

Quires 1, 10 and 11 have additional holes, perhaps traces of a previous sewing or errors occurred during the preparation of the quires.

$</$ decoNote $>$

40

Within the decoNote[@type="Fastenings"] it is possible to describe fastenings or remaining traces of them, while in the decoNote[atype="SlipCase"] the presence and the shape of the traditional leather case where the codex is kept may be recorded. Lastly, the decoNote [@type="0ther"] permits, with keywords, encoding features related to guards-that is, their position in the quire and the technique of attachment-and bookmarks, namely the bookmark type. Furthermore, it is possible using <locus> and @target to mark where the bookmarks are found.

41 In order to facilitate the work of the catalogers, guidelines for bindings descriptions have been prepared $^{51}$ and are openly accessible to the research community (Liuzzo et al. 2018).

\subsection{Current Applications and Future Research Perspectives}

42 Thanks to the flexibility of the TEI it is now possible to accurately describe bookbinding features and thus gather previously unrecorded data which may enable in-depth studies of the Ethiopian bookbinding tradition. The data encoded according to the protocol presented in this paper are structured data that can be processed and presented in many different ways (Liuzzo 2019, 4). Thus, the Beta mașāhəft web application offers the user various options for exploring the data about the bindings.

Journal of the Text Encoding Initiative, Issue rolling, 22/01/2022 Open Issue 
43 For example, in the bindings' index it is possible to filter among all cataloged manuscripts those whose binding features have been described..$^{2}$ As figure 5 shows, at the moment the research environment displays several thousands entities, grouped according to their features. Most of them were described by the Ethio-SPaRe project when the protocol for binding description was not fully developed. For this reason, some features are represented more than others in the results. When one selects a feature, the app displays the shelfmarks of the manuscripts in which its description appears, and the shelfmarks point directly to the entire manuscript record. The left sidebar offers several options to further refine the research according to categories and keywords.

Figure 5. Binding-filtered search on Beta mașāḥəft web application.
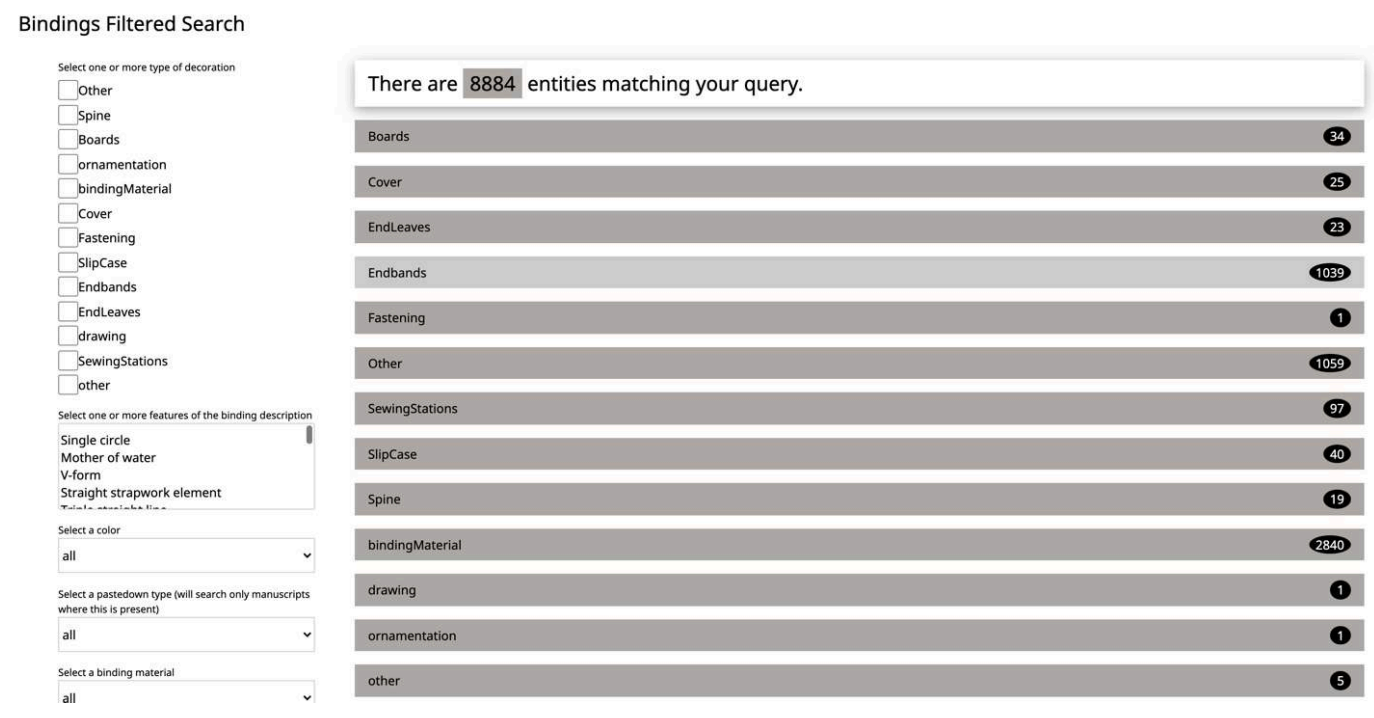

From the results of a search a user can explore various aspects related to the topic of interest -among others bookbinding. A search limited to manuscripts with available images for a given selection allows the user to examine in detail the appearance of selected binding features. For example filtering for manuscripts and the keyword Golden Gospel, ${ }^{53}$ the search will retrieve 13 results. It is possible to refine the search by limiting it to manuscripts with available images (6 results) and then filtering for a specific binding material (see figure 6). Thus, the user can directly inspect how the material is used in the manuscripts. Alternatively a view of the results as graphics can allow to directly analyze distributions. 
Figure 6. Faceted search for Golden Gospel with available images.

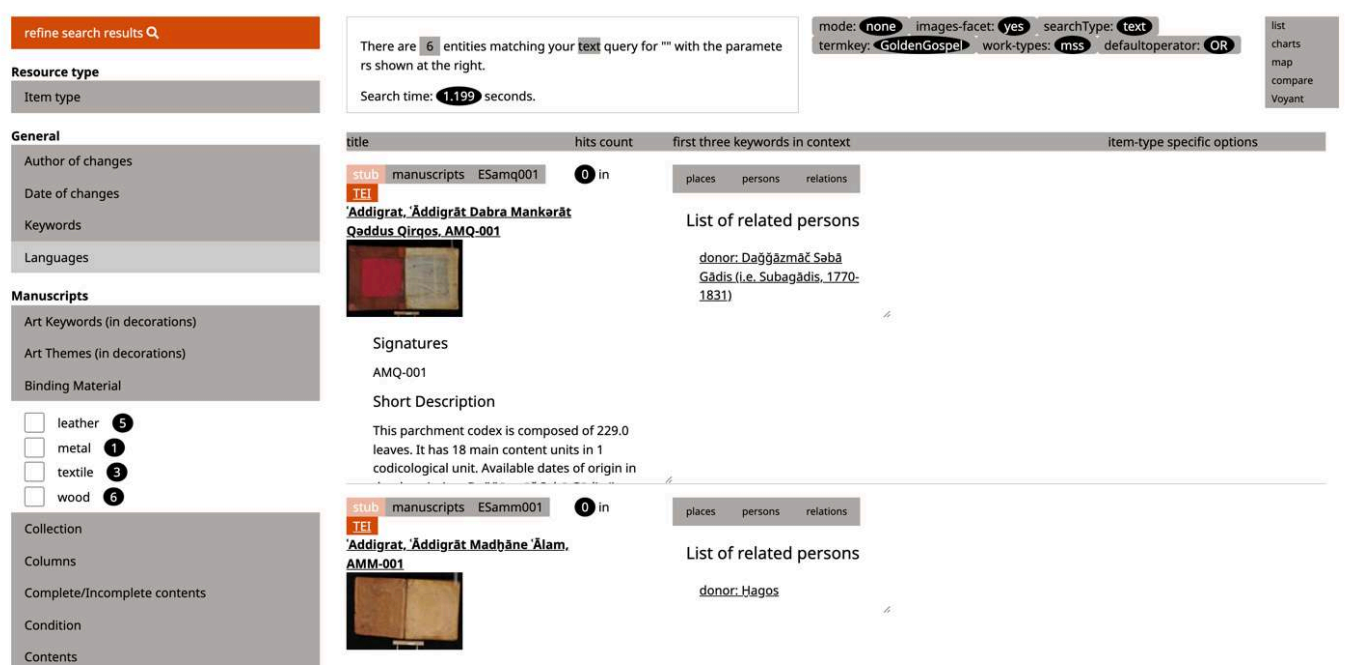

This view of selected items as charts displays, for a group of items, the correlation of the encoded bookbinding features with other manuscript data, such as date and location. In a recent work, Liuzzo introduces this application (Liuzzo 2019, 4-10) and explains how pie or column charts in Beta mașāḩft are created using Google Charts, ${ }^{54}$ providing the tool with tables of data extracted from the manuscript records. At present, in the web application, when a group of manuscripts is selected, it is possible to generate bar charts of how the number of sewing stations, the sewing patterns, the thread material, and the binding material vary across time-if these features are encoded. The charts have on the $\mathrm{x}$-axis date ranges and on the $\mathrm{y}$-axis the percentage of manuscripts with that feature. The date ranges are both arbitrary periods of three centuries (1200-1499, 15001799, and 1800-2099) and periods taken from the canonical periodization of the project. ${ }^{55}$ Bars are created grouping the manuscripts by date, looking at <origDate>. If a manuscript falls within two date ranges, it is counted in both groups. The percentile value allows one to compare the distribution of a feature across different periods regardless of the total number of its attestations (Liuzzo 2019, 9). Figure 7 shows, for example, how the sewing patterns-pattern A and pattern A3vary according to the dates of nine manuscripts at the State and University Library Hamburg Carl von Ossietzky. 
Figure 7. Bar chart of sewing patterns by date range for nine manuscripts at the State and University Library Hamburg Carl von Ossietzky.

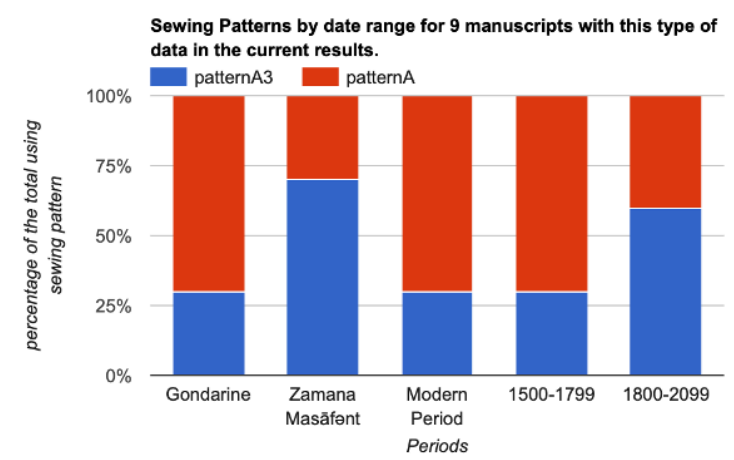

Nevertheless, the data charted in figure 7 cannot be taken as representative of the distribution of the sewing patterns in Ethiopian manuscripts since they refer to a sample of only nine manuscripts. More relevant for the representation of a phenomenon is the case when the chart analyzes data from a larger sample. For example, figure 8 shows the distribution of binding material across time for 952 manuscripts encoded by the Ethio-SPaRe project.

Figure 8. Bar chart of the binding materials by date range for 952 manuscripts encoded by the Ethio-SPaRe project.

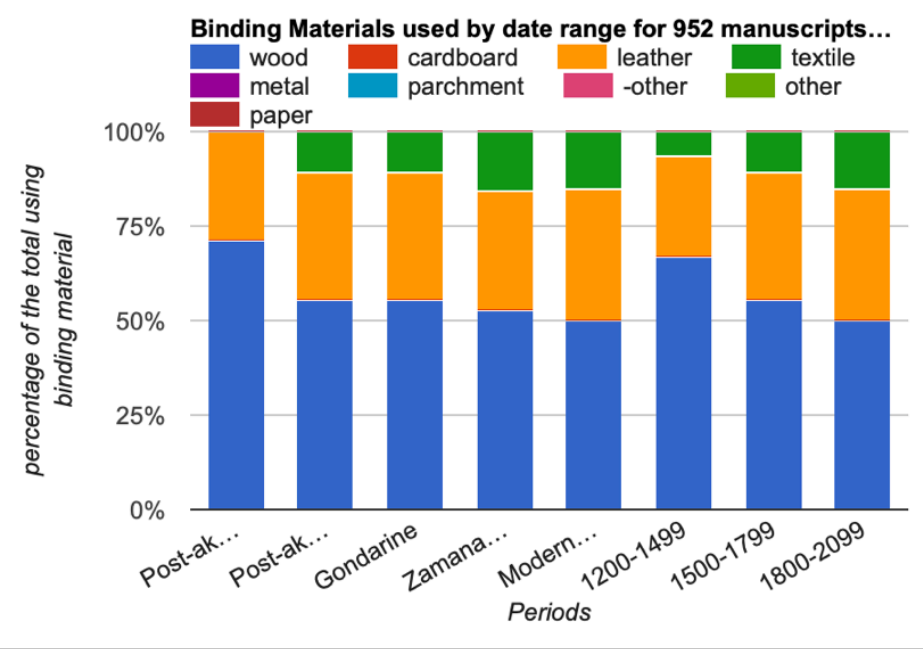


48 The customization of the TEI schema presented here allows catalogers to record accurate and consistent descriptions of Ethiopian bookbinding features. The gathering of this previously unrecorded data offers the opportunity to investigate the possible relationship between specific material features and the time and region in which the manuscripts were produced, thus opening completely new research perspectives in the field of Ethiopian bookbinding studies. Nevertheless, in order for the data to be effectively representative of the Ethiopian bookbinding tradition, they must be derived from a large sample of manuscripts. For this reason, the new protocol for binding description needs to be applied to an increasing number of manuscripts so that more data can be collected.

49 In this way it will perhaps be possible to answer unresolved questions relating to the materials and techniques available for bookbinding manufacture and the reasons behind the choices of specific solutions. This study will permit both to understand a specific manuscript's history and also to shed further light on the development of a craft across time and space.$^{56}$ Furthermore, the setup of a good documentation practice, based on standardized terminology and methods, would allow combining bookbinding records from different projects' databases, thus fostering comparative research. ${ }^{57}$ Hence, an agreement on a standard structure to adopt in binding description in TEI would foster the advance of bookbinding studies.

\section{BIBLIOGRAPHY}

Andrist, Patrick, Paul Canart, and Marilena Maniaci. 2013. La syntaxe du codex: Essai de codicologie structurale. Bibliologia 34. Turnhout: Brepols.

Barbero, Giliola, and Francesca Trasselli. 2014. "Manus OnLine and the Text Encoding Initiative Schema." Journal of the Text Encoding Initiative 8. http://journals.openedition.org/jtei/1054; doi:10.4000/jtei.1054. Bausi, Alessandro, Pier Giorgio Borbone, Françoise Briquel-Chatonnet, Paola Buzi, Jost Gippert, Caroline Macé, Marilena Maniaci, et al. 2015. Comparative Oriental Manuscript Studies: An Introduction. Edited by Alessandro Bausi, Pier Giorgio Borbone, Françoise Briquel-Chatonnet, Paola Buzi, Jost Gippert, Caroline Macé, Marilena Maniaci, et al. Hamburg: COMSt. https://www.aai.uni-hamburg.de/en/comst/publications/ handbook.html.

Journal of the Text Encoding Initiative, Issue rolling, 22/01/2022 Open Issue 
Boudalis, Georgios. 2018. The Codex and Crafts in Late Antiquity. New York: Bard Graduate.

Bozzacchi, Giampiero. 2000. Censimento Dei Dati Materiali Dei Codici Etiopici Della Sezione Orientale Della Biblioteca Dell'Accademia Dei Lincei e Corsiniana. Typewritten. Roma.

---. 2007. La Legatura Etiopica. Beni Culturali: Tutela e Valorizzazione 15 (6).

Burnard, Lou, ed. 2008. “The ENRICH Schema - A Reference Guide.” http://projects.oucs.ox.ac.uk/ENRICH/ Deliverables/referenceManual_en.html.

Campagnolo, Alberto. 2015a. "Bit by Bit: Is the Book as an Object Entering the Digital World?" In I Beni Bibliografici Nelle Strategie Dei Fondi Europei. Atti Del Convegno. Siracusa, ISISC, 3-4 Dicembre 2015, edited by Alberto Campagnolo, Lucia Catalano, Rosalia C. Giordano, and Gabriele Lo Piccolo, 91-112. Palermo: Assessorato dei Beni Culturali e dell'Identità siciliana; Dipartimento B.C. e I.S.

---. 2015b. "Transforming Structured Descriptions to Visual Representations: An Automated Visualization of Historical Bookbinding Structures." PhD diss., University of the Arts London. http:// ualresearchonline.arts.ac.uk/8749/.

-_-. 2017. "Bookbinding Information on the Web: Breaking the Circle, from Pixels to Linked Open Data." International Information \& Library Review 49 (1): 37-50. doi:10.1080/10572317.2017.1270689.

- - . 2020. “Conservation and Digitization: A Difficult Balance?” In Book Conservation and Digitization: The Challenges of Dialogue and Collaboration, edited by Alberto Campagnolo, 49-82. Collection Development, Cultural Heritage, and Digital Humanities. Leeds: Arc Humanities Press.

Di Bella, Marco, and Nikolas Sarris. 2014. “Field Conservation in East Tigray, Ethiopia.” In Care and Conservation of Manuscripts 14. Proceedings of the Fourteenth International Seminar Held at the University of Copenhagen 17th-19th October 2012, edited by Matthew James Driscoll, 271-307. Copenhagen: Museum Tusculanum Press.

Driscoll, Matthew James. 2010. “The ENRICH project: Towards a European Digital Manuscript Library.” DigItalia 2:117-22. http://digitalia.sbn.it/article/view/243.

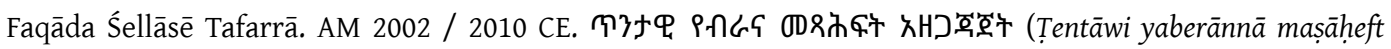
azzagāğāğat, The ancient manner of preparing parchment books). Addis Ababa: Addis Ababā Yunivarsiti Prēss.

Le Bars, Fabienne, Anna Markova, Florence Clavaud, and Lauranne Bertrand. 2016. Encodage des reliures numérisées de la Bibliothèque nationale de France. Manuel et Dictionnaire des balises (version 3). http:// bibnum.bnf.fr/reliure_20161025/manuel/bnf_reliure_tei_manuel.html\#n2.6.

Ligatus. 2007. Printed Books Survey Schema (version 1.8). XML. London: Ligatus Research Centre, CCW Graduate School, University of the Arts London. http://www.ligatus.org.uk/stcatherines/sites/ ligatus.org.uk.stcatherines/files/basic-1.8_0.xsd.

Liuzzo, Pietro Maria. 2019. Digital Approaches to Ethiopian and Eritrean Studies. Supplement to Aethiopica 8. Wiesbaden: Harrassowitz Verlag. doi:10.2307/j.ctvrnfr3q. 
Liuzzo, Pietro Maria, Dorothea Reule, Eugenia Sokolinski, Solomon Gebreyes, Daria Elagina, Denis Nosnitsin, Eliana Dal Sasso, and Jacopo Gnisci. 2018-. Beta Mașāhoft Guidelines. https://betamasaheft.eu/Guidelines/. Mellors, John, and Anne Parsons. 2002. Bookmaking in Rural Ethiopia in the Twenty-First Century: Ethiopian Bookmaking. London: New Cross Books.

Mersha Alehegne. 2011. “Towards a Glossary of Ethiopian Manuscript Culture and Practice." Aethiopica 14: 145-62. doi:10.15460/aethiopica.14.1.417.

Miles, Alistair, and Sean Bechhofer. 2009. SKOS Simple Knowledge Organization System Reference. W3C Recommendation 18 August 2009. W3C. Accessed March 31, 2021. https://www.w3.org/TR/skos-reference/. Nosnitsin, Denis. 2016. "Lesser Known Features of the Ethiopian Codex." In Movements in Ethiopia, Ethiopia in Movement. Proceedings of the 18th International Conference of Ethiopian Studies, edited by Eloi Ficquet, Ahmed Hassen, and Thomas Osmond, 1:75-90. Addis Ababa and Los Angeles: CFEE-IES and Tsehai Publishers.

Pankhurst, Richard. 1984. Ethiopian Manuscript Bindings and Their Decoration. Abbay, 205-57.

Pickwoad, Nicholas. 1995. "The Interpretation of Bookbinding Structure An Examination of SixteenthCentury Bindings in the Ramey Collection in the Pierpont Morgan Library." The Library, 6th ser., 17 (3): 209-49. doi:10.1093/library/s6-17.3.209.

---. 2004. "The Condition Survey of the Manuscripts in the Monastery of Saint Catherine on Mount Sinai." The Paper Conservator 28 (1): 33-61. doi:10.1080/03094227.2004.9638640.

---. 2012. "An Unused Resource: Bringing the Study of Bookbindings out of the Ghetto." In Ambassadors of the Book: Competences and Training for Heritage Librarians, edited by Raphaële Mouren, 83-94. IFLA Publications 160. Berlin: De Gruyter Saur. doi:10.1515/9783110301502.83.

. 2014. "The Structures and Materials of Commercial Bookbindings in the Arcadian Library." In The Arcadian Library: Bindings and Provenance, edited by Giles Mandelbrote and Willem A. C. de Bruijn, 233-278. Studies in the Arcadian Library 9. London: Arcadian Library in association with Oxford University Press. Pickwoad, Nicholas, and Michael Gullick. 2004. Assessment Manual: A Guide to the Survey Forms to Be Used in St Catherine's Monastery, http://www.ligatus.org.uk/sites/default/files/manual20050110.pdf.

Rousseau, Philip. 2007. "Introduction: From Binding to Burning." In The Early Christian Book, edited by William E. Klingshirn and Linda Safran, 1-9. CUA Studies in Early Christianity. Washington, DC: Catholic University of America Press. doi:10.2307/j.ctt2853v4.6.

Sergew Hable Selassie. 1981. Bookmaking in Ethiopia. Leiden: Karstens Drukkers.

Szirmai, Janos A. 1999. The Archaeology of Medieval Bookbinding. Aldershot: Ashgate.

TEI Consortium. 2020. TEI P5: Guidelines for Electronic Text Encoding and Interchange. Version 4.1.0. Last updated August 19. https://tei-c.org/Vault/P5/4.1.0/doc/tei-p5-doc/en/html/index.html. 
Tomaszewski,Jacek, and Michael Gervers. 2015. "Technological Aspects of the Monastic Manuscript Collection at May Wäyni, Ethiopia." In From Dust to Digital: Ten Years of the Endangered Archives Programme, edited by Maja Kominko, 89-133. Cambridge: Open Book Publishers. doi:10.11647/OBP.0052.04.

Velios, Athanasios, and Nicholas Pickwoad. 2005. "Current Use and Future Development of the Database of the St. Catherine's Library Conservation Project," The Paper Conservator 29 (1): 39-53. doi:10.1080/03094227.2005.9638486.

--_. 2019. “Versioning Materiality: Documenting Evidence of Past Binding Structures." In Versioning Cultural Objects: Digital Approaches, edited by Roman Bleier and Sean M. Winslow, 103-26. Schriften des Instituts für Dokumentologie und Editorik, Bd. 13. Nordstedt: BoD.

---. 2020. "The Development of the Language of Bindings Thesaurus." In Book Conservation and Digitization. The Challenges of Dialogue and Collaboration, edited by Alberto Campagnolo, 157-68. Collection Development, Cultural Heritage, and Digital Humanities. Leeds: Arc Humanities Press.

Velios, Athanasios, Nicholas Pickwood [sic], and Aurelie Martin. 2014. "Multilingual Bookbinding Terms: Complex Conceptual Issues," Newsletter of the ICOM CIDOC: 15-20. https://cidoc.mini.icom.museum/wpcontent/uploads/sites/6/2018/12/CIDOC_Newsletter_2014.pdf.

Winslow, Sean M. 2015. “Ethiopian Manuscript Culture: Practices and Contexts.” PhD diss., University of Toronto https://tspace.library.utoronto.ca/handle/1807/71392.

\section{NOTES}

1 For a typological classification of the transformations a manuscript can undergo, see Andrist, Canart, and Maniaci (2013, 61-91). Specifically on bindings, Pickwoad (1995, 213; 2014,238) notes how books sold in temporary retail bindings may be rebound according to the taste and the needs of the owner. Velios and Pickwoad (2019) show how the CIDOC CRM ontology (http://www.cidoccrm.org) can be used to represent the modifications (variants) of a binding across time. Beta mașāhəft evaluates implementing this methodology to enrich binding descriptions.

2 The term original indicates the first binding the manuscript received, whose manufacture is usually contemporary with the writing.

3 A project by Ligatus and the University of the Arts London for the conservation and preservation of the library of the monastery of St. Catherine in Sinai, Egypt. See, accessed January 25, 2022, https://www.ligatus.org.uk/stcatherines/. 
4 The Language of Bindings (LoB) thesaurus is a reference tool for the description of historical bookbinding structures created by the Ligatus Research Unit at the University of the Arts London with the contributions of international experts in the field of bookbinding studies. LoB is a structured vocabulary, freely available to the research community, based on the Simple Knowledge Organization System (SKOS) and published as linked open data (LOD). See, accessed January 25, 2022, https://www.ligatus.org.uk/lob/.

5 "Beta mașāhoft: Manuscripts of Ethiopia and Eritrea (Schriftkultur des christlichen Äthiopiens und Eritreas: eine multimediale Forschungsumgebung) is a long-term project headed by Prof. Alessandro Bausi and funded within the framework of theAcademies' Programme (coordinated by the Union of the German Academies of Sciences and Humanities) under survey of the Akademie der Wissenschaften in Hamburg. The project is hosted by the Hiob Ludolf Centre for Ethiopian Studies at the University of Hamburg (HLCEES)." See, accessed January 25, 2022, https://www.betamasaheft.unihamburg.de and https://betamasaheft.eu.

6 Ethiopian bookbinding is a term deeply rooted in literature and refers to the traditional technique used to bind Christian Ethiopian and Eritrean manuscripts.

7 See Bausi et al. $(2015,168-70)$, for an overview and further references; details can be found also in Di Bella and Sarris (2014); Winslow (2015, 201-62); and Nosnitsin (2016).

8 For a detailed explanation of the technique and its variations with diagrams, see Szirmai (1999, 16-19).

9 For the definition of sewing stations see LoB, accessed January 25, 2022, http://w3id.org/lob/ concept/1579.

10 See Eliana Dal Sasso, "Grottaferrata, Exarchic Greek Abbey of St. Mary of Grottaferrata, Crypt. Aet. 7," in Die Schriftkultur des christlichen Äthiopiens und Eritreas: Eine multimediale Forschungsumgebung / Beta mașāḥft, edited by Alessandro Bausi, accessed January 22, 2022, https:// betamasaheft.eu/manuscripts/GAet7.

11 For the definition of turn-ins see LoB, accessed January 25, 2022, http://w3id.org/lob/ concept/1694.

12 For the definition of blind-tooled decoration see LoB, accessed January 25, 2022, http://w3id.org/ lob/concept/2288. 
13 The only study on the topic, to my knowledge, is that of Pankhurst (1984). A tentative classification of bookbinding tools and designs is under preparation by the author for the catalog of the Ethiopic manuscripts of the Bodleian Library, a project initiated by Jacopo Gnisci and Dorothea Reule with the cooperation of Eliana Dal Sasso, Solomon Gebreyes Beyene, Susanne Hummel, and Massimo Villa.

14 For the definition of metal sides see LoB, accessed January 25, 2022, http://w3id.org/lob/ concept $/ 4488$.

15 For the definition of endbands see LoB, accessed January 25, 2022, http://w3id.org/lob/ concept $/ 2370$.

16 For the definition of pastedowns see LoB, accessed January 25, 2022, http://w3id.org/lob/ concept/1493.

17 For the definition of spine linings see LoB, accessed January 25, 2022, http://w3id.org/lob/ concept/1619.

18 Guards (see LoB, accessed January 25, 2022, http://w3id.org/lob/concept/1379) either reinforce the folds of quires (precisely defined in LoB as sewing guards, accessed January 25, 2022, http:// w3id.org/lob/concept/3282) or attach single leaves to a textblock (precisely defined in LoB as extension guards, accessed January 25, 2022, http://w3id.org/lob/concept/1322).

19 See TEI Consortium 2020, 10.7.3.1: "Binding Descriptions," accessed January 25, 2022, https:// tei-c.org/Vault/P5/4.1.0/doc/tei-p5-doc/en/html/MS.html\#msphbi.

20 See Beta mașāhoft, accessed January 25, 2022, https://betamasaheft.eu/authority-files/list? keyword=slitBraid.

21 ODD stands for "One Document Does it all." It is a TEI file which contains both machine- and human-readable information about the choices made by the project in the customization of the standard TEI schema.

22 The Simple Knowledge Organization System (SKOS) is a "common data model for sharing and linking knowledge organization systems via the Web" (Miles and Bechhofer 2009).

23 For the definition of board linings, see LoB, accessed January 25, 2022, http://w3id.org/lob/ concept/1219.

24 For the definition of textile in LoB see, accessed January 25, 2022, http://w3id.org/lob/ concept $/ 2470$. 
25 See Beta mașāḥəft, accessed January 25, 2022, https://betamasaheft.eu/Guidelines/? id=bindingDescription.

26 TEI Consortium 2020, Appendix C: Elements, <binding>, accessed January 25, 2022, https://teic.org/Vault/P5/4.1.0/doc/tei-p5-doc/en/html/ref-binding.html.

27 See, accessed January 25, 2022, https://wiki.tei-c.org/index.php? title=TEI_manuscript_catalogues.

28 Examples of bookbinding descriptions in TEI can be found in TEI Consortium 2020, Example: <binding>, accessed January 25, 2022, https://tei-c.org/Vault/P5/4.1.0/doc/tei-p5-doc/en/html/ examples-binding.html.

29 See Manuscriptorium, accessed January 25, 2022, http://www.manuscriptorium.com/en.

30 See e-Codices, accessed January 25, 2022, http://www.e-codices.unifr.ch/.

31 Appenzell, Landesarchiv Appenzell I. Rh., E.10.02.01.01, accessed January 25, 2022, http:// www.e-codices.unifr.ch/en/description/laai/E-10-02-01-01/Rechtsquellen.

32 European Networking Resources and Information concerning Cultural Heritage. The documents related to the project are available at, accessed January 25, 2022, http://projects.oucs.ox.ac.uk/ ENRICH/.

33 Union catalog of manuscripts from the Islamicate World: see accessed January 25, 2022, https:// www.fihrist.org.uk.

34 Union catalog of manuscripts of Shan Buddhist lik lu ń manuscripts in UK and Southeast Asian collections: see accessed January 25, 2022, https://senmai.bodleian.ox.ac.uk.

35 See, accessed January 25, 2022, https://github.com/msDesc/consolidated-tei-schema/ blob/231ec69b8e769d6649ae644004bc3affa39198e6/msdesc.odd\#L3071.

36 London, Wellcome Trust, Wellcome Collection, MS Arabic 495, accessed January 25, 2022, https://github.com/fihristorg/fihrist-mss/blob/master/collections/wellcome\%20trust/ WMS_Arabic_495.xml.

37 See Manus OnLine, accessed January 25, 2022, https://manus.iccu.sbn.it.

38 Arezzo, Biblioteca Città di Arezzo, Manoscritti, 118, accessed January 25, 2022, https:// manus.iccu.sbn.it/opac_SchedaScheda.php?ID=49065.

39 See BnF, accessed January 25, 2022, http://reliures.bnf.fr.

40 See accessed January 25, 2022, http://bibnum.bnf.fr/reliure_20161025/index.html. 
41 See, accessed January 25, 2022, http://bibnum.bnf.fr/reliure_20161025/manuel/ bnf_reliure_tei_manuel.html\#n2.6.

42 Paris, Bibliothèque nationale de France, Réserve des livres rares, RES P- YC- 1275, accessed January 25, 2022, http://reliures.bnf.fr/ark:/12148/cdt9x5x4/. The XML is the first example in TEI Consortium 2020, Example: <adminInfo> (administrative information), accessed January 25, 2022, https://www.tei-c.org/Vault/P5/4.1.0/doc/tei-p5-doc/en/html/examples-adminInfo.html.

43 The project Ethio-SPaRe (ERC Starting Grant 240720) was headed by Denis Nosnitsin of the HLCES from December 2009 to May 2015. It was dedicated to the preservation and scientific analysis of manuscripts located in Ethiopian churches and monasteries, with the focus of the activities being in the Tegray region in the north of the country.

44 The "Torno Subito" program, promoted by Regione Lazio, financed by the Regional Operational Programme Lazio European Social Fund 2014-2020, aims at increasing the knowledge and the professional skills of young university students or graduates. In 2017 the author was granted funding to participate in the activities of the Hiob Ludolf Centre for Ethiopian and Eritrean Studies and thus contribute to the development of binding description in the Beta mașāhəft project. The second part of the project was carried out at the Italian Central Institute of Cataloging (ICCU) in Rome, within the Manus OnLine project (https://manus.iccu.sbn.it), for which it was possible for the first time to include in the online catalog Ethiopic manuscripts with detailed codicological descriptions (16 mss. from the Exarchic Greek Abbey of St. Mary of Grottaferrata, 1 ms. from the Angelica Library, 2 mss. from the Casanatense Library, 5 mss. from the Library of the Accademia Nazionale dei Licei e Corsiniana, 12 mss. from the Central National Library "Vittorio Emanuele II," 12 mss. from the Giovardiana Library, and 19 mss. from the Library of the Abbey of Casamari).

45 TEI Consortium 2020, Appendix C: Elements, <decoNote>, accessed January 25, 2022, https:// www.tei-c.org/Vault/P5/4.1.0/doc/tei-p5-doc/en/html/ref-decoNote.html.

46 See the definition of the content model macro.specialPara at TEI Consortium 2020, Appendix E: Datatypes and Other Macros, macro.specialPara, accessed January 25, 2022, https://www.teic.org/Vault/P5/4.1.0/doc/tei-p5-doc/en/html/ref-macro.specialPara.html.

47 The recording of color can be difficult because of discoloration and degradation of materials over time. As stated in the Ligatus guidelines, the color is recorded from protected areas, such as the turn-ins. See Pickwoad and Gullick $(2004,12)$.

Journal of the Text Encoding Initiative, Issue rolling, 22/01/2022 Open Issue 
48 Eliana Dal Sasso, "Hamburg, State and University Library Hamburg Carl von Ossietzky, Cod. Orient. 404," in Die Schriftkultur des christlichen Äthiopiens und Eritreas: Eine multimediale Forschungsumgebung / Beta mașāḥ̂ft, edited by Alessandro Bausi, accessed Janury 25, 2022, https:// betamasaheft.eu/manuscripts/SHOr404.

49 In Ethiopian tradition endleaves are mostly, if not exclusively, sewn to textblock.

50 Eliana Dal Sasso, 'Hamburg, State and University Library Hamburg Carl von Ossietzky, Cod. orient. 405', in Die Schriftkultur des christlichen Äthiopiens und Eritreas: Eine multimediale Forschungsumgebung / Beta mașāḩft, edited by Alessandro Bausi accessed January 25, 2022, https:// betamasaheft.eu/SHOr405.

51 Many catalogers are not binding experts, and the guidelines nevertheless allow them to record features relevant to the study of bindings.

52 See Beta mașāhəft, accessed January 25, 2022, https://betamasaheft.eu/bindings.

53 See, accessed January 25, 2022, https://betamasaheft.eu/newSearch.html? searchType=text\&clavistype=\&query=\&defaultoperator=0R\&mode=none\&worktypes=mss\&termkey=GoldenGospel

54 See Google Charts, accessed January 25, 2022, https://developers.google.com/chart.

55 See Periodo, accessed January 25, 2022, http://n2t.net/ark:/99152/p03tcss4qvV.

56 Beta mașāhəft's bookbinding description keeps developing and improving, and benefits greatly from contributions by the research community.

57 For example, the PhD project on Coptic bookbinding led by the present author, at the Centre for the Study of Manuscript Cultures of the University of Hamburg, will offer interesting data for comparison. For an introduction to Coptic bookbinding, see Szirmai (1999, 7-43), and for an overview of Late Antique binding crafts, see Boudalis (2018).

\section{AUTHOR}

\section{ELIANA DAL SASSO}

Eliana Dal Sasso is a doctoral researcher at Hamburg University affiliated with the Cluster of Excellence "Understanding Written Artefact" of the Centre for the Study of Manuscript Cultures with the project "Bookbindings as Archival Instruments: Defining, Ordering and Transmitting Knowledge in Christian Egypt 
(4th-11th centuries)." She holds an MA in conservation and restoration of library and archival material. In 2018 she was a research guest at the Hiob Ludolf Center for Ethiopian and Eritrean Studies for the study of Ethiopian bookbinding and in 2019 a research fellow at Sapienza University of Rome for the ERC project "PAThs: An Atlas of Coptic Literature." 